UCRL-ID-134051

\title{
Simulation of Ceramic Windows for the APT/LEDA CCDTL
}

\author{
Lara D.Daily
}

March 1, 1999

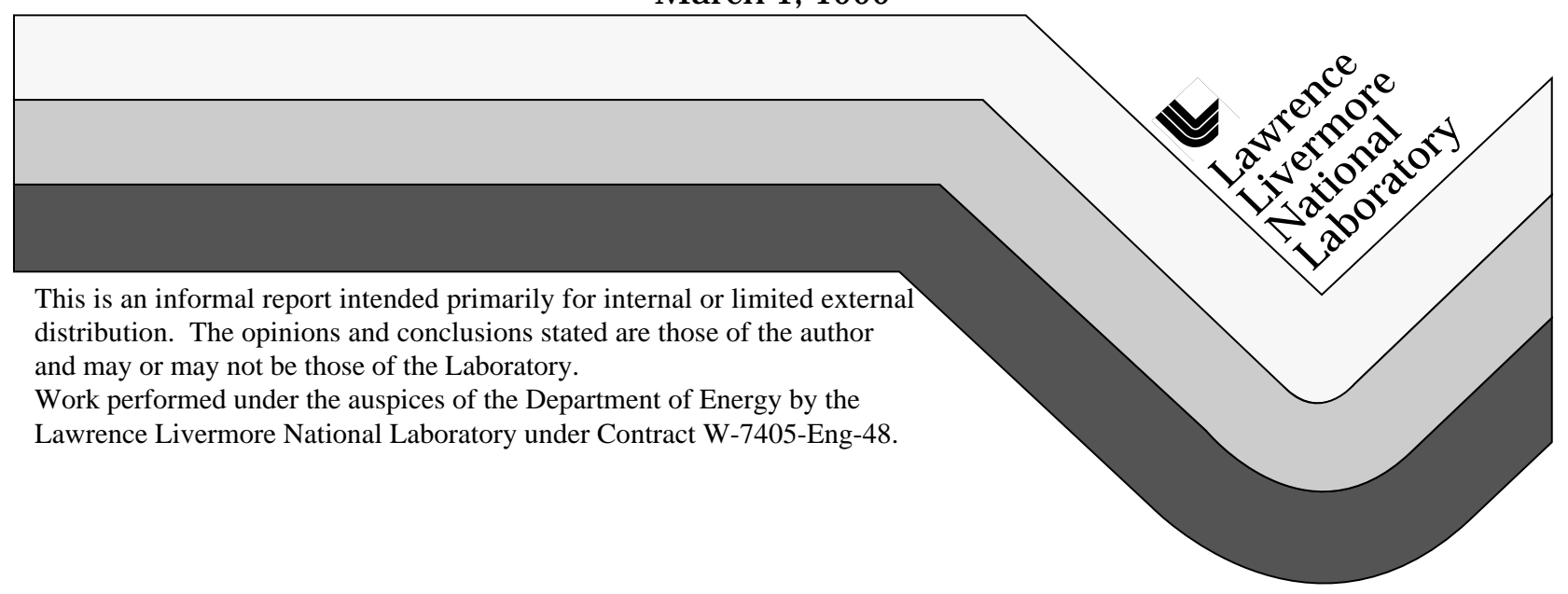




\section{DISCLAIMER}

This document was prepared as an account of work sponsored by an agency of the United States Government. Neither the United States Government nor the University of California nor any of their employees, makes any warranty, express or implied, or assumes any legal liability or responsibility for the accuracy, completeness, or usefulness of any information, apparatus, product, or process disclosed, or represents that its use would not infringe privately owned rights. Reference herein to any specific commercial product, process, or service by trade name, trademark, manufacturer, or otherwise, does not necessarily constitute or imply its endorsement, recommendation, or favoring by the United States Government or the University of California. The views and opinions of authors expressed herein do not necessarily state or reflect those of the United States Government or the University of California, and shall not be used for advertising or product endorsement purposes.

This report has been reproduced directly from the best available copy.

Available to DOE and DOE contractors from the Office of Scientific and Technical Information P.O. Box 62, Oak Ridge, TN 37831

Prices available from (423) 576-8401

Available to the public from the National Technical Information Service

U.S. Department of Commerce 5285 Port Royal Rd., Springfield, VA 22161 


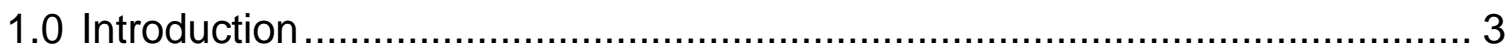

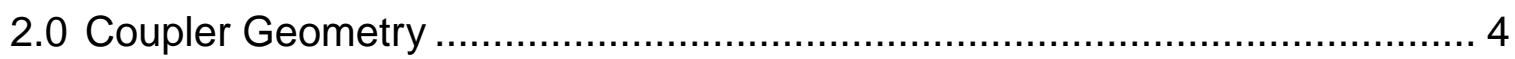

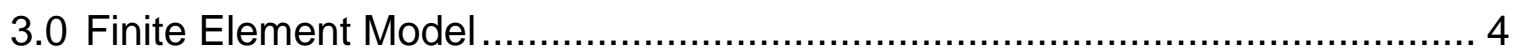

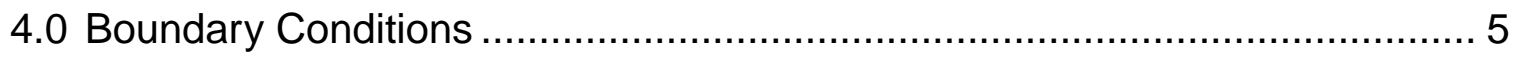

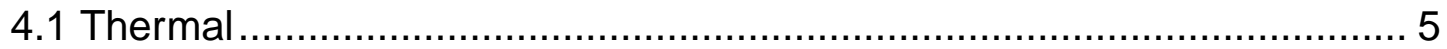

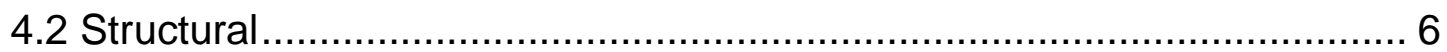

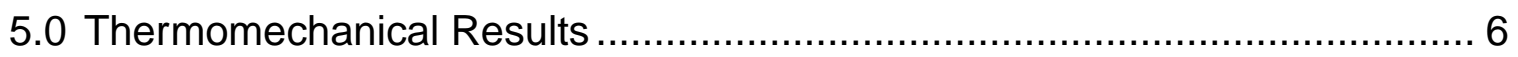

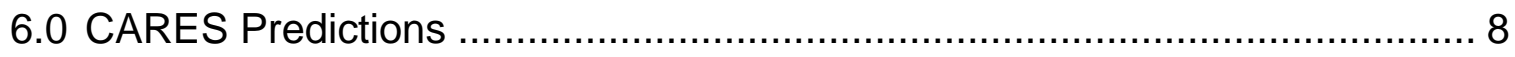

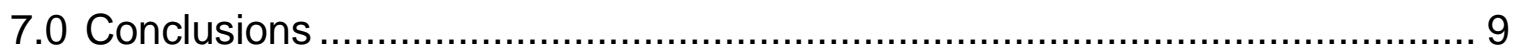

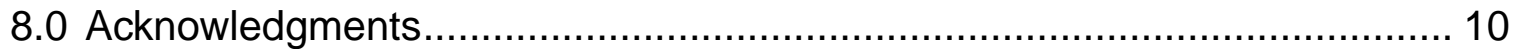

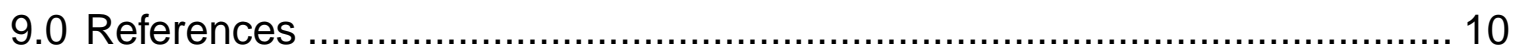

Appendix A: Material Properties

Appendix B: AL300 Experimental Data 


\section{Abstract}

Development of a robust, high-average-power (up to $1 \mathrm{MW}, \mathrm{CW}$ ) microwave transmission line system for the Accelerator Production of Tritium (APT) linac (linear accelerator) facility is a stringent engineering and operational requirement. One key component in this RF transmission system is the vacuum barrier window. The requirement of high-power handling capability coupled to the desirability of low probability of failure over lengthy time scales can be treated substantially with a set of microwave, thermomechanical, and Weibull analysis codes. This paper examines engineering models of ceramic windows for the Coupled-Cavity Drift-Tube Linac (CCDTL) segment of the APT Normal Conducting (NC) linac. The detailed cooling circuit is modeled and accurate heat deposition models for the RF are implemented. This simulation is then used to analyze the thermomechanically induced stresses on the CCDTL window configuration. A Weibull-distribution failure prediction code is used to integrate experimentally obtained ceramic material failure data and structural analysis calculations to infer reliability of the structure.

\subsection{Introduction}

The APT project is a Department of Energy (DOE) sponsored investigation into the feasibility of using linear accelerator technology (as opposed to the customary use of reactors) to produce tritium as part of the Strategic Stockpile Stewardship program.

The APT linac accelerates protons to $1700 \mathrm{MeV}$ in $1107.4 \mathrm{~m}$ operating at
$100 \mathrm{~mA} \mathrm{CW}$ (there is an alternate design for a $1030 \mathrm{MeV}$, depending on stockpile needs). The linac is comprised of a $211.4 \mathrm{MeV}$ normal conducting linac (radio-frequency quadripole, RFQ, and CCDTL), 471.4 MeV medium $\beta$ superconducting linac, and a high- $\beta$ supercondcuting linac ${ }^{10}$.

A major engineering challenge is the design of vacuum barrier ceramic windows inside the RF transmission system to the accelerating cavities. Specifications call for a material that is transparent to microwaves at a frequency of $700 \mathrm{MHz}$ and a power of 1 MW, CW (actual operation of the CCDTL will be at $\sim 25 \%$ power). Compromise of the system results in vacuum breach and costly down time for the production accelerator.

The Low-Energy Demonstration Accelerator (LEDA) is part of an extensive Engineering Development \& Demonstration (ED\&D) campaign to support the development of the massive APT project. LEDA is a prototype of the APT linac that consists of only the injector, RFQ, and CCDTL segments of the APT design (the NC linac). Stellar performance of this prototype is critical to the proof of concept of the APT program. Thus, there is an emphasis on rigorous design and analysis of these components to assure a successful prototype. The analysis in this report follows (and is closely coupled to) extensive analysis of the RFQ windows that is outlined in Reference 6 by Dr. Karen Cummings at Los Alamos National Laboratory.

The objective of the CCDTL analysis is to develop a simulation that will model the thermal and structural effects of transmission inefficiencies coupled to 
the load from the air/vacuum pressure differential to discern reliability.

Since ceramic materials have much higher deviations in strength and wear properties than conventional structural materials, the output of the continuum, thermomechanical, Finite Element Analysis (FEA) will be coupled to a Weibull-distribution statistics code. Weibull analysis is performed with CARES (Ceramic Analysis and Reliability Evaluation of Structures) ${ }^{1}$, a finite element probabilistic software developed by NASA Lewis Research Center. The probability of failure is calculated from Weibull parameters derived using data from four point bending tests on AL300 (97.6\% alumina ceramic).

\subsection{Coupler Geometry}

The physical response of much of LEDA has been determined, either analytically or experimentally, and this previous experience is used in the present analysis.

Electric fields from microwave transmission produce heat loads from dielectric losses and material imperfections in the copper and alumina. There is active cooling from air flowing through the inner conductor and out across the window surface. The walls of the inner and outer conductors are copper plated stainless steel on the input side and OFE (oxygen free) copper on the accelerator side.

\subsection{Finite Element Model}

The Finite Element (FE) model is built as a 2-D axisymmetric simulation with 4-node quadrilateral elements. Using a 2-D axisymmetric simulation, as opposed to the 3-D, is assumed from the experimental observation that very little problem insight is gained from the addition of 3-D effects for the steady state analysis. There is geometric axisymmetry of the problem and the main concern is the stress state of the windows, not the entire system.

From an electric field calculation, the heat deposition along the walls of the inner conductor, outer conductor, and the ceramic is conservatively approximated to be axisymmetric with the maximum azimuthal values represented.

The values of the electric field in the coupler are adapted from calculations performed by David Mayhall at LLNL using a 3-D direct Maxwell equation solver, HFSS, and the EEV dual-window superconducting linac design at $500 \mathrm{~kW}$ and $700 \mathrm{MHz}$. The values for power deposition are determined from the calculated electric field averaged over a RF cycle for the perfectly matched transmission case (traveling wave) $)^{9}$.

Convective cooling is accounted for by computing heat transfer coefficients from correlations for fluid flow ${ }^{2}$ and comparing those values with previous analytical experience from other linac segments ${ }^{7,8}$. Enclosure radiation is accounted for in the vacuum cavities using a gray diffuse view factor analysis. Natural convection and radiation exchange with the surroundings are accounted for on all outside surfaces.

The simulation is performed in two steps: (1) obtain the solution of the 


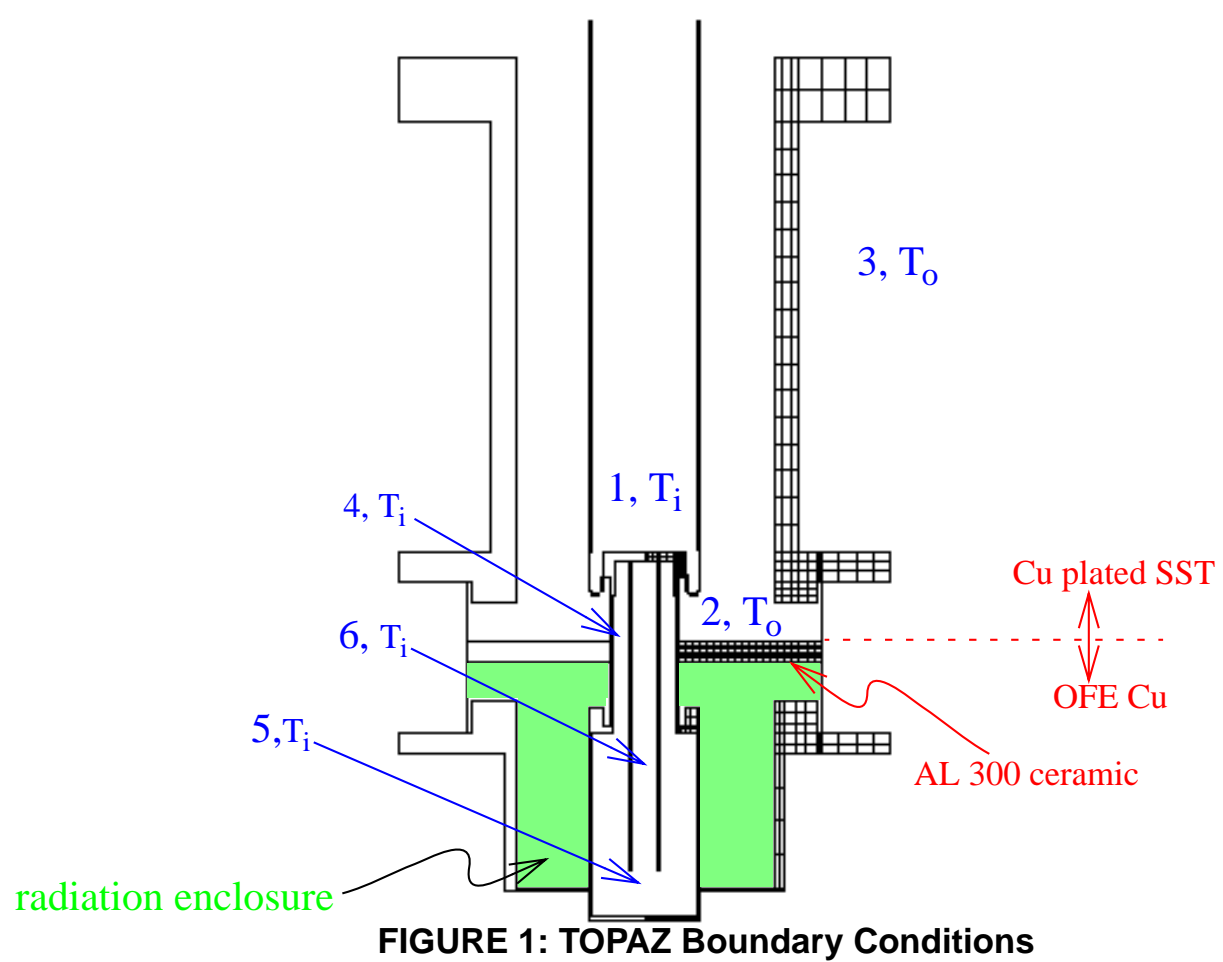

thermal protile trom the given power load (using TOPAZ2D ${ }^{3}$ ), then (2) obtain the solution of stress contours throughout the window from the sum of thermal stress and mechanical/structural stress from the air/vacuum pressure differential (using NIKE2D ${ }^{4}$ ).

These solutions combine to give the thermal stress result.

\subsection{Boundary Conditions}

\subsection{Thermal}

The following tables describe the heat transfer/film coefficient values used in the thermal, TOPAZ2D, calculation. Locations can be found in Figure 1. The temperatures found in Table 1 are those seen in experiments ${ }^{5}$. The convection boundary conditions found in Table 2 are derived from Nusselt number correlations and knowledge gained trom validating previous API/LEDA numerical models to experiments

TABLE 1: Temperature Boundary Conditions

\begin{tabular}{|c|c|}
\hline & $\begin{array}{c}\text { temperature } \\
\text { (K) }\end{array}$ \\
\hline $\mathrm{Ti}$ & 325 \\
$\mathrm{To}$ & 330 \\
Tsurr & 297 \\
\hline
\end{tabular}

TABLE 2: Convection Boundary Conditions

\begin{tabular}{|c|c|c|}
\hline & $\mathbf{h} \mathbf{( \mathbf { W } / \mathbf { m } ^ { \mathbf { 2 } } \mathbf { - K } )}$ & $\mathbf{T}_{\infty}$ \\
\hline 1 & 50 & $\mathrm{Ti}$ \\
2 & 30 & $\mathrm{To}$ \\
3 & 3 & $\mathrm{To}$ \\
4 & 145 & $\mathrm{Ti}$ \\
5 & 145 & $\mathrm{Ti}$ \\
6 & 340 & $\mathrm{Ti}$ \\
\hline
\end{tabular}

Other boundary conditions account for thermal radiation exchange between surfaces, which is negligible in the cases that have convection, but not in 
those where there is vacuum. Values used for the emissivity can be found in Appendix A: Material Properties.

A model was built to simulate the braze joint between the ceramic and the conductor walls. Based on the material composition of the braze and relative lengths of theses materials, an effective conductance can be assigned for the conductivity between the ceramic and the conductors of the coupler. Details of this analysis for a braze of silver copper eutectic, nickel, and molybdenum can be found in Reference 6 .

\subsection{Structural}

The structural model calculates the thermal stress as waveguide parts expand due to dielectric heating in a constrained boundary, coupled to pressure load of 1 atmosphere that is exerted on the vacuum surfaces of the window and conductors. The locations of these structural boundary conditions used in the NIKE2D calculation can be found in Figure 2.

\subsection{Thermomechanical Results}

Results show a nominal steady state temperature rise of $100^{\circ} \mathrm{C}$ on the surface of the ceramic for the $1 \mathrm{MW}$, $700 \mathrm{MHz}, \mathrm{CCDTL}$. This results in a maximum temperature gradient in the ceramic of $12.5^{\circ} \mathrm{C}$. The resulting maximum principle stress is $24.6 \mathrm{MPa}$ at the outer edge of the ceramic.

Table 3 shows the result of sensitivity studies on the model to the assumptions that were made at model inception. There are two major ambiguities that need to be resolved: material at the brazed joint and emissivity of alumina.

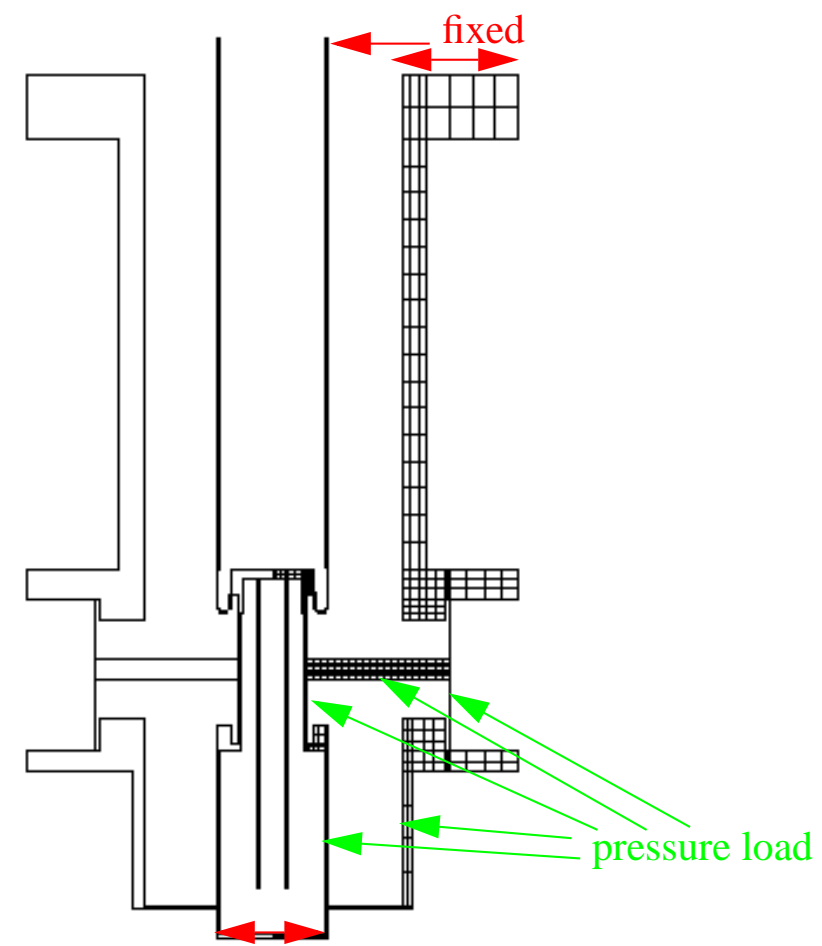

FIGURE 2: NIKE Boundary Conditions 
It is seen that the model is extremely sensitive to the material on the outer conductor at the braze. If the ceramic is brazed to Cu SST (as opposed to OFE $\mathrm{Cu}$ ) the boundary now has a lower conductivity and higher strength than copper (both conditions that lead to larger stress values in the ceramic). From Table 3, it is observed that a higher temperature gradient and higher thermal stress will result. It is also shown that the choice of emissivity did not greatly effect the final solution.

TABLE 3: Sensitivity of thermomechanical model

\begin{tabular}{|c|c|c|c|}
\hline case & $\Delta \mathbf{T}\left({ }^{\circ} \mathbf{C}\right)$ & $\sigma_{\max }(\mathbf{M P a})$ & $\%$ change \\
\hline braze on Cu SST & 15.2 & 64.8 & $+163 \%$ \\
$\varepsilon=0.92$ & 12.5 & 24.6 & 0 \\
\hline
\end{tabular}

Another ambiguity that cannot be resolved with sensitivity studies is the selection of heat transfer or film coefficients. As mentioned in $\$ 4.1$, the values tabulated are based on Nusselt correlations that are engineering approximations for crude geometries and require extremely well defined boundary conditions to assume accuracy. For this analysis, the Nusselt correlations were rigorously applied by integrating engineering assumption with experience from past LEDA components, but the ultimate accuracy of the model should be scrutinized until an experimental validation can be performed.

Since stress and temperature gradient results are higher for the SST braze condition, Figures 3-5 present the calculations for the steady state $1 \mathrm{MW}$, $700 \mathrm{MHz}$, with Cu SST up to and including braze area.

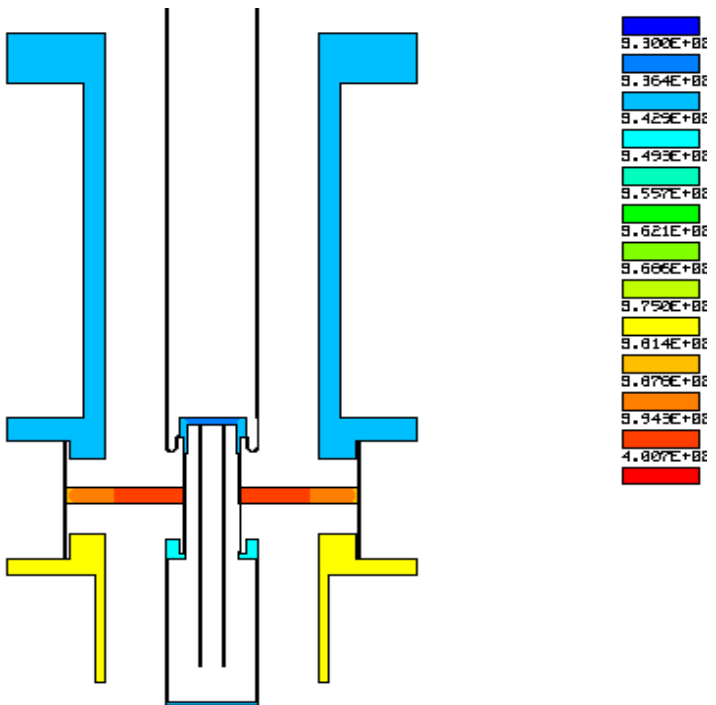

FIGURE 3: Contours of temperature in Kelvin

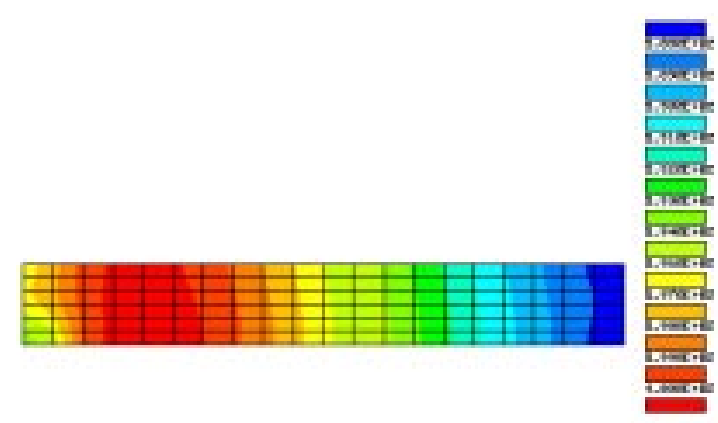

FIGURE 4: Contours of temperature in Kelvin for the window only 


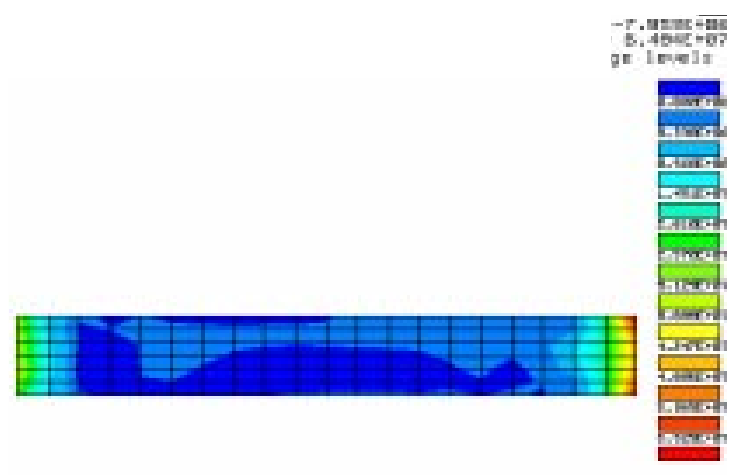

FIGURE 5: Contours of maximum principle stress in $\mathrm{Pa}$ for the window only

\subsection{CARES Predictions}

CARES is a probabilistic, public domain, software program that was developed at NASA Lewis Research Center. CARES calculates the Probability of Failure (POF) for brittle ceramic materials from Weibull parameters and fatigue parameters for sub-critical crack growth. These parameters are calculated by CARES from test sample data.

Using data for WESGO AL300 ceramic (see Appendix B: AL300 Experimental Data), the probability of failure is calculated for two cyclic fatigue models: full cycle and partial cycle. The full cycle (Fatigue Model A) is $100 \%$ power to zero over 50.3 hours and the partial cycle (Fatigue Model B) goes from $100 \%$ to $85.7 \%$ in $30 \mathrm{~min}$. These values correspond to the cases of complete shutdown and loss of beam respectively as defined in Reference 6. Each of these cycle cases is performed for the power magnitudes of 1, 2, and 4 MW.

Appendix B shows the experimental values used to characterize the parameters for the ceramic. All specimen tests where performed at NASA Lewis
Research Center and correspond to a batch of AL300 from WESGO, and grit blasted before testing.

Figures 7 and 8 show the results of the reliability analysis. It is apparent that the reliability of the ceramic is less effected by the cycle characteristics than it is by the magnitude of stress. It is assumed that any additional thermal cycles would give predictably similar results. Computational analysis indicates that a full thermal cycle could be as quick as 8 hours (5.5 hour heat up, 2.5 hour cool down), but that is not considered here because of the aforementioned result. Computed times for a complete power cycle are shown in Figure 6.

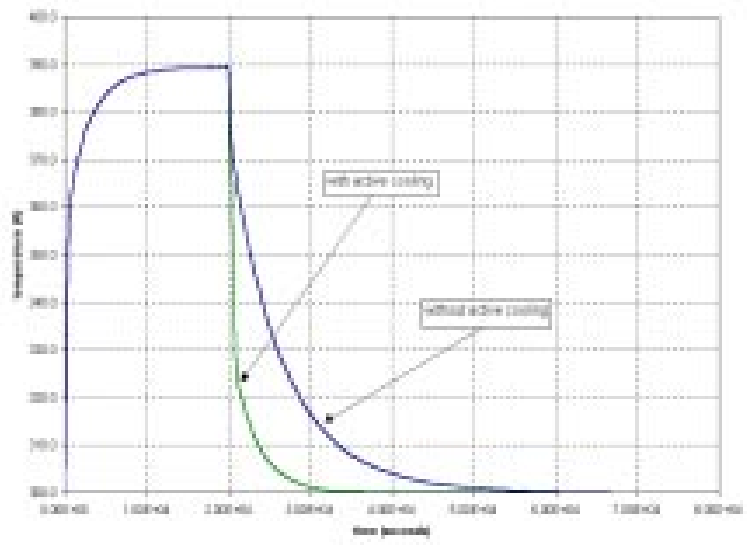

FIGURE 6: Calculated heating and cooling curves for one full thermal cycle

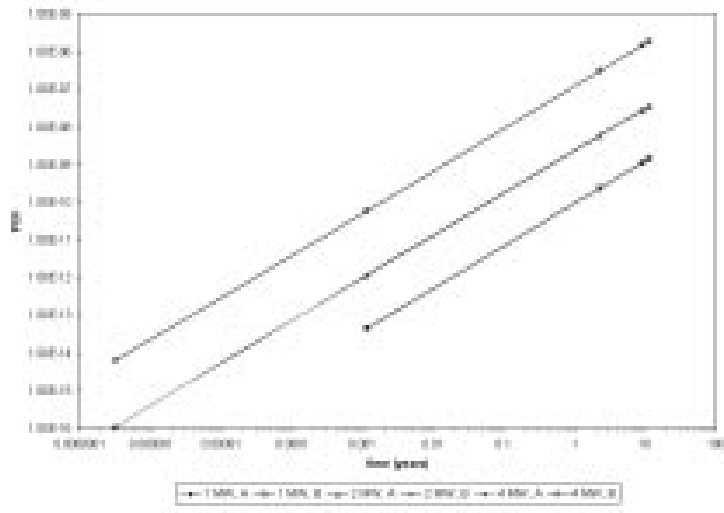

FIGURE 7: Reliability of Fatigue Models A \& B separately 


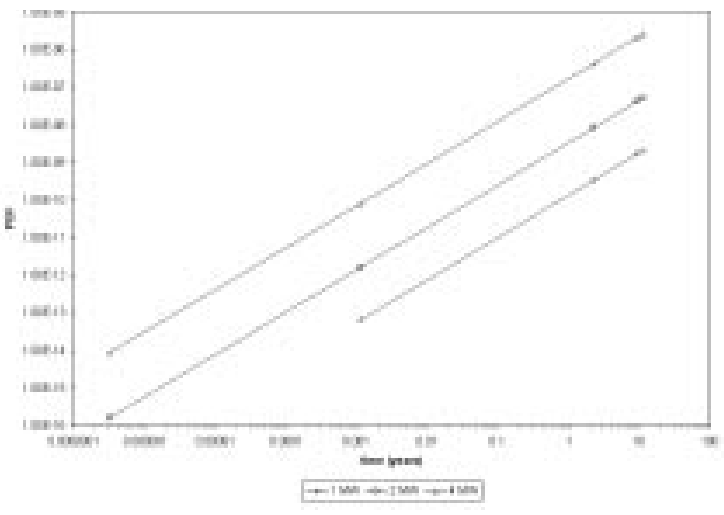

FIGURE 8: Reliability of combined Fatigue Models A \& B

Because the principle stresses in this model are so much lower than the strength of the material, these results seem to suggest that there will never be any failure in the model.

Continuing the CARES calculations for larger stresses shows that the ceramic will not go to POF = 1 until the stress is increased by a factor of three for the stainless steel braze model, and seven for the copper braze model. This corresponds to principle stresses approaching $170 \mathrm{MPa}$, which is consistent with the minimum failure magnitude of 158 $\mathrm{MPa}$ (which has statistically low likelihood of occurring) and the mean strength of $215 \mathrm{MPa}$ for alumina (as determined from specimen tests).

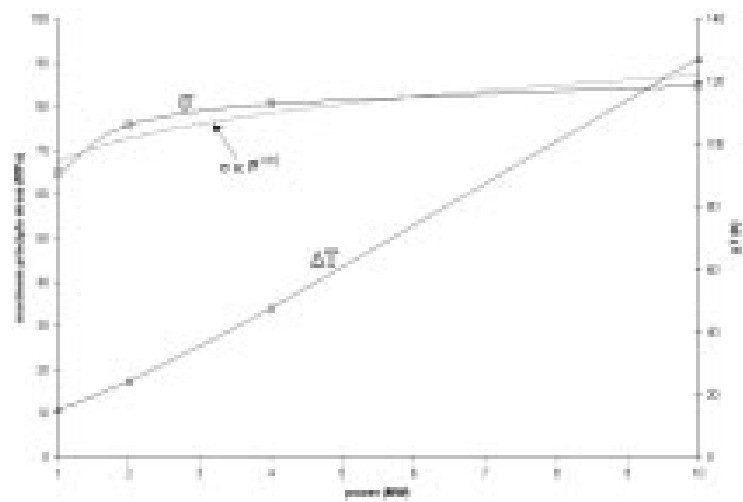

FIGURE 9: Scale of stress and temperature gradient in the ceramic with RF power
Figure 9 shows the scaling of stress with power. Although the temperature gradient scales linearly to power, the resulting stress goes like power to the $1 / 10$, leading to the conclusion that this model will not reach POF of 1 .

\subsection{Conclusions}

A complete suite of electromagnetic, thermal, structural, and statistical analysis have been performed on the APT/ LEDA CCDTL ceramic windows. The resulting maximum principle stresses are found to be significantly lower that the ultimate strength of the material $(<$ $1 / 3$ ) and the resulting reliability is predicted to be quite high. Subsequently, it is assumed that shutdown of the accelerator do to failure of these windows will be very rare.

It is possible for failure as a result of any un-modeled conditions that result in a stress magnification of the necessary 3 to 7 times calculated in $\$ 6.0$. Possibilities include, but are not limited to:

- surface conditions, topology, and polish

- residual stress in manufacture

- complete or partial electrical mismatch (standing wave)

- stiff braze

Any sort of anomalous behavior should be closely monitored during experimentation of the CCDTL system so that the failure mechanism of the ceramic might be further characterized. 


\subsection{Acknowledgments}

Completion of this analysis would not have possible without the contributions of colleagues at LLNL and LANL. The author acknowledges stimulating discussions with Dr. C. Shang, Dr. A. Shapiro, and Dr. C. Landram at LLNL, and Dr. K. Cummings and B. Rusnak at LANL.

\subsection{References}

[1] Baker, E., L. Janosik, J. Gyekenyesi, N. Nemeth, and L. Powers, "CARES Users and Programmers Guide-Preliminary Draft," NASA Lewis Research Center, Cleveland, $\mathrm{OH}$ (1997).

[2] DeWitt, D. and F. Incropera, Fundamentals of Heat and Mass Transfer, 4th ed., John Wiley \& Sons: New York (1996).

[3] Shapiro, Arthur B., "TOPAZ3D: A three-dimensional finite element heat transfer code," LLNL UCID20484, Livermore, CA (1985).

[4] Maker, Bradley N., "NIKE3D: A non-linear, implicit, three dimensional finite element code for solid and structural mechanics," LLNL UCRL-MA-105268 rev. 1, Livermore, CA (1995).

[5] Cummings, K., "EEV RF Window experiments," LANL Memo L-5:97028 (1997).

[6] Cummings, K., "Theoretical Predictions and Experimental Assessments of the Performance of Alumina RF Windows", Ph.D. Dissertation, UC Davis, LA-13466-T (1998).
[7] Reitter, T., "Memo to EEV", July 1997.

[8] Daily, L.D., "Simulation of HighAverage Power Windows for Accelerator Production of Tritium", LINAC98 Conference Proceedings, Chicago, IL (1998).

[9] Mayhall, D., personal correspondence, LLNL, May 1998.

[10] Lawrence, G. P., "High-Power Proton Linac for APT; Status of Design and Development", LINAC98 Conference Proceedings, Chicago, IL (1998). 


\section{OXYGEN FREE COPPER (OFE CU)}

$\rho=8940 \mathrm{~kg} / \mathrm{m}^{3}[1]$

\begin{tabular}{c|c}
$\mathrm{T}(\mathrm{K})$ & $\mathrm{cp}(\mathrm{J} / \mathrm{kg}-\mathrm{K})[1]$ \\
\hline 222.2 & 372.8 \\
\hline 273.1 & 383.3 \\
\hline 1356 & 502.1
\end{tabular}

\begin{tabular}{c|c}
$T(K)$ & $k(\mathrm{~W} / \mathrm{m}-\mathrm{K})[1]$ \\
\hline 153.2 & 447.7 \\
\hline 273.1 & 401.7 \\
\hline 1356 & 330.0
\end{tabular}

$\varepsilon=0.03[3]$

$\alpha=16.6 \times 10^{-6} 1 / \mathrm{K}[2]$

$\mathrm{E}=1.17 \times 10^{11} \mathrm{~Pa}[2]$

$v=0.32[2]$

\section{COPPER PLATED STAINLESS STEEL (CU SST)}

(approximated as SST-304 material properties and OFE Cu surface conditions)

$\rho=7920 \mathrm{~kg} / \mathrm{m} 3[1]$

\begin{tabular}{c|c}
$\mathrm{T}(\mathrm{K})$ & $\mathrm{cp}(\mathrm{J} / \mathrm{kg}-\mathrm{K})[1]$ \\
\hline 273.1 & 502.1 \\
\hline 673.1 & 564.8
\end{tabular}

\begin{tabular}{c|c}
$T(K)$ & $k(\mathrm{~W} / \mathrm{m}-\mathrm{K})[1]$ \\
\hline 173.2 & 10.8 \\
\hline 273.1 & 13.4 \\
\hline 373.2 & 16.3
\end{tabular}

$\varepsilon=0.03$ [3]

$\alpha=17.8 \times 10^{-6} 1 / \mathrm{K}$ [2]

$E=1.93 \times 10^{11} \mathrm{~Pa}$ [2]

$v=0.29$ [2] 


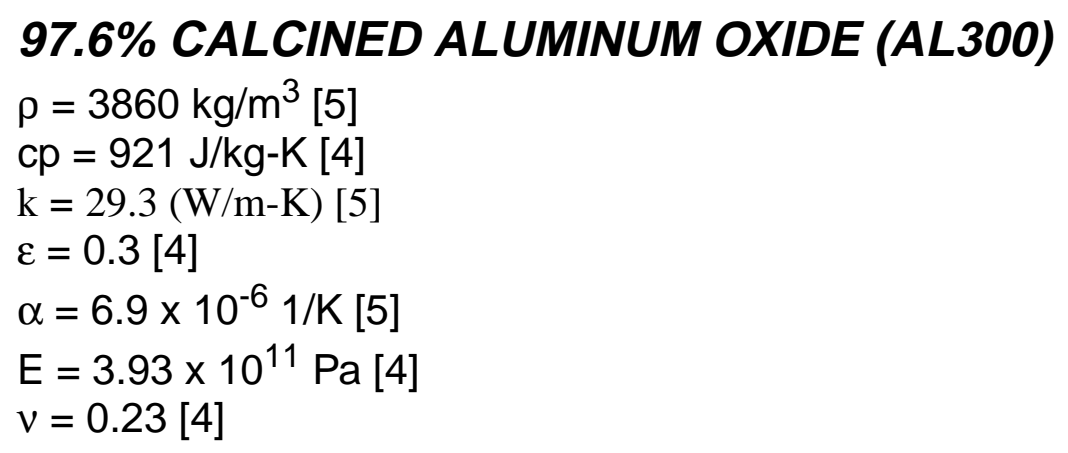

\section{EQUIVALENT CONDUCTIVITY OF BRAZE JOINT}

$q_{\text {equivalent }}=23,404 \mathrm{~W} / \mathrm{m}^{2}-\mathrm{K}$ [6]

\section{REFERENCES}

[1] Shapiro A.B. and A.L. Edwards. "TOPAZ2D Heat Transfer Code and Thermal Properties Data Base," LLNL UCRL-ID-104558-REV-1, May 1990.

[2] Avallone, E. A. and T. Baumeister III, ed. "Mark's Standard Handbook for Mechanical Engineers, 10th edition," New York: McGraw-Hill, 1996.

[3] Incropera, F.P. and D.P. DeWitt, "Fundamentals of Heat and Mass Transfer, 4th edition," New York: John Wiley \& Sons, 1996.

[4] Lynch, J. F., C. G. Ruderer, and W. H. Duckworth, "Engineering Properties of Ceramics: Data Book to Guide Materials Selection for Structural Applications," Air Force Materials Laboratory AFML-TDR_66-52, June 1966.

[5] Memo from WESGO Technical Ceramics, 1/14/98.

[6] Cummings, K., "Theoretical Predictions and Experimental Assessments of the Performance of Alumina RF Windows", Ph.D. Dissertation, UC Davis, LA-13466-T, July 1998. 


\begin{tabular}{|c|c|}
\hline Stressing Rate (MPa/s) & Fracture Strength $(\mathrm{Pa})$ \\
\hline $2.975000 \mathrm{E}+07$ & $2.668900 \mathrm{E}+08$ \\
\hline $2.981000 \mathrm{E}+07$ & $2.496000 \mathrm{E}+08$ \\
\hline $2.980000 \mathrm{E}+07$ & $2.557900 \mathrm{E}+08$ \\
\hline $2.959000 \mathrm{E}+07$ & $2.511200 \mathrm{E}+08$ \\
\hline $2.956000 \mathrm{E}+07$ & $2.510300 \mathrm{E}+08$ \\
\hline $2.970000 \mathrm{E}+07$ & $2.451900 \mathrm{E}+08$ \\
\hline $2.974000 \mathrm{E}+07$ & $2.508200 \mathrm{E}+08$ \\
\hline $2.969000 \mathrm{E}+07$ & $2.366700 \mathrm{E}+08$ \\
\hline $2.964000 \mathrm{E}+07$ & $2.385500 \mathrm{E}+08$ \\
\hline $2.971000 \mathrm{E}+07$ & $2.548000 \mathrm{E}+08$ \\
\hline $2.991000 \mathrm{E}+07$ & $2.453700 \mathrm{E}+08$ \\
\hline $2.984000 \mathrm{E}+07$ & $2.386400 \mathrm{E}+08$ \\
\hline $2.979000 \mathrm{E}+07$ & $2.400900 \mathrm{E}+08$ \\
\hline $2.990000 \mathrm{E}+07$ & $2.401400 \mathrm{E}+08$ \\
\hline $2.962000 \mathrm{E}+07$ & $2.526400 \mathrm{E}+08$ \\
\hline $2.968000 \mathrm{E}+07$ & $2.355300 \mathrm{E}+08$ \\
\hline $2.959000 \mathrm{E}+07$ & $2.130600 \mathrm{E}+08$ \\
\hline $2.960000 \mathrm{E}+07$ & $2.391800 \mathrm{E}+08$ \\
\hline $2.953000 \mathrm{E}+07$ & $2.424400 \mathrm{E}+08$ \\
\hline $2.951000 \mathrm{E}+07$ & $2.408000 \mathrm{E}+08$ \\
\hline $3.000000 \mathrm{E}+04$ & $1.895800 \mathrm{E}+08$ \\
\hline $3.000000 \mathrm{E}+04$ & $1.836500 \mathrm{E}+08$ \\
\hline $3.000000 \mathrm{E}+04$ & $1.667600 \mathrm{E}+08$ \\
\hline $3.000000 \mathrm{E}+04$ & $1.713300 \mathrm{E}+08$ \\
\hline $3.000000 \mathrm{E}+04$ & $1.715700 \mathrm{E}+08$ \\
\hline $3.000000 \mathrm{E}+04$ & $1.716100 \mathrm{E}+08$ \\
\hline $3.000000 \mathrm{E}+04$ & $1.795600 \mathrm{E}+08$ \\
\hline
\end{tabular}




\begin{tabular}{|c|c|}
\hline Stressing Rate $(\mathrm{MPa} / \mathrm{s})$ & Fracture Strength $(\mathrm{Pa})$ \\
\hline \hline $3.000000 \mathrm{E}+04$ & $1.763200 \mathrm{E}+08$ \\
\hline $3.000000 \mathrm{E}+04$ & $1.582300 \mathrm{E}+08$ \\
\hline $3.000000 \mathrm{E}+04$ & $1.792900 \mathrm{E}+08$ \\
\hline $2.960000 \mathrm{E}+05$ & $1.956600 \mathrm{E}+08$ \\
\hline $2.950000 \mathrm{E}+05$ & $1.897000 \mathrm{E}+08$ \\
\hline $2.960000 \mathrm{E}+05$ & $1.857200 \mathrm{E}+08$ \\
\hline $2.960000 \mathrm{E}+05$ & $1.648400 \mathrm{E}+08$ \\
\hline $2.960000 \mathrm{E}+05$ & $1.880600 \mathrm{E}+08$ \\
\hline $2.963000 \mathrm{E}+06$ & $2.189000 \mathrm{E}+08$ \\
\hline $2.955000 \mathrm{E}+06$ & $2.010900 \mathrm{E}+08$ \\
\hline $2.957000 \mathrm{E}+06$ & $2.080400 \mathrm{E}+08$ \\
\hline $2.967000 \mathrm{E}+06$ & $1.974600 \mathrm{E}+08$ \\
\hline $2.968000 \mathrm{E}+06$ & $2.043500 \mathrm{E}+08$ \\
\hline
\end{tabular}

$$
\sigma_{\text {average }}=215 \mathrm{MPa}
$$

From personal correspondence with John Salem, NASA Lewis Research Center, Cleveland, $\mathrm{OH}$, July, 30, 1998 